\title{
Language for resilience: desafios e possibilidades no ensino/aprendizagem de línguas para refugiados falantes de árabe
}

\author{
Language for Resilience: Challenges and Possibilities in \\ Language Teaching/Learning for Arabic-Speaking Refugees
}

\author{
Evellin Bianca Souza de Oliveira \\ Universidade Estadual de Santa Cruz; Brasil \\ https://orcid.org/0000-0001-8969-4288 \\ e-mail: evellinbso@gmail.com \\ Filipe Arruda de Castro \\ Universidade Estadual da Paraíba, Brasil \\ https://orcid.org/0000-0003-4945-2932 \\ e-mail: filipecastrofac@gmail.com \\ Recibido: $12 / 12 / 2020$ \\ Aprobado:02/02/2021
}

\begin{abstract}
RESUMO
Todos os anos milhares de pessoas são forçadas a deixarem seu país de origem por motivos de guerras, perseguição política, religiosa, dentre outros motivos, sendo vistas não mais como cidadãs, mas refugiadas. Ao fugir de sua terra, um dos principais instrumentos que um povo leva consigo é sua língua, todavia, ao chegar ao país de acolhimento pessoas refugiadas, muitas vezes, são impedidas de utilizá-la, o que os deixa em uma situação ainda maior de vulnerabilidade (ATEEK, 2018). Dados do Comitê Nacional para os Refugiados - CONARE (2018) mostram que no Brasil há 11,231 pessoas reconhecidas como refugiadas, sendo que $36 \%$ são de nacionalidade síria e o restante é composto por pessoas de diferentes países. Quando pensamos em refugiados, entendemos que ao chegar ao país de acolhimento além de todas as suas perdas, eles sofrem ainda desafios em sua identidade linguística, logo, o processo de pertencimento passa pela aprendizagem da nova língua, e esta se torna instrumento não apenas de comunicação, mas de resiliência. Assim, após passarmos um período considerável em diferentes países do Oriente Médio realizando trabalhos voluntários relacionado ao ensino de línguas para refugiados, entendemos que a língua tem papel fundamental nos fluxos migratórios. Desta forma, nesta pesquisa, iremos abordar a importância do ensino de português como língua de acolhimento, ressaltando também a necessidade do ensino de línguas adicionais para refugiados. Traremos referenciais teóricos que abordam o tema como Arantes et al (2016), Brasil (2019), British Council (2016) e (2018), relacionando-os a nossa prática com o ensino de línguas para refugiados árabes. Buscamos também investigar a importância das ONG's e entidades como British Council, que promovem ações de ensino-aprendizagem para pessoas em situação de refúgio e abordar o papel do Brasil na ACNUR. Acreditamos que esta pesquisa pode colaborar para a visibilidade e políticas linguísticas em favor de refugiados, especialmente falantes de árabe, no Brasil.
\end{abstract}

Palavras - Chave: Refugiados; Resiliência; Línguas; Árabe.

\begin{abstract}
Every year thousands of people are forced to leave their country of origin due to wars, political and religious persecution, and other reasons, being seen no longer as citizens, but as refugees. When fleeing their land, one of the main instruments that a people takes with them is their language, however, when refugees arrive in the host country, they are often prevented from using it, which leaves them in an even greater situation of vulnerability (ATEEK, 2018). Data from the UNHCR (2018) show that in Brazil there are 11,231 people recognized as
\end{abstract}


refugees, $36 \%$ of them are Syrian nationals and the rest are people from different countries. When we think of refugees, we understand that when they reach the host country in addition to all their losses, they still suffer challenges in their linguistic identity, so the process of belonging involves learning the new language, and this new language becomes an instrument not only for communication, but for resilience. Thus, after spending a considerable period in different countries in the Middle East doing volunteer work related to the teaching of languages to refugees, we understand that language plays a fundamental role in migratory flows. Thus, in this research, we will address the importance of teaching Portuguese as a host language, also emphasizing the need for teaching additional languages for refugees. We will bring theoretical references that address the theme such as Arantes et al (2016), Brazil (2019), British Council (2016) and (2018), relating our practice on language teaching for Arab refugees. We also seek to investigate the importance of NGO's and entities such as the British Council, which promote teaching and learning actions for people in a situation of refuge and we also aim to write about the Brazil's role at UNHCR. We believe that this research can contribute to the visibility and linguistic policies in favor of refugees, especially Arabic speakers, in Brazil.

Keywords: Refugees; Resilience; Languages; Arabic.

\section{INTRODUÇÃO}

Ao longo da História temos lido sobre populações que saem de seus países buscando apoio, acolhimento e condições favoráveis de vida em outros países. Quando pensamos nos primórdios da vida na Terra, podemos considerar que o sedentarismo chegou às populações após um longo período de nomadismo, onde o homem se deslocava com certa frequência, por questões de sobrevivência. Caminhando um pouco mais pela História, em um período não tão distante, vemos que a era das navegações, onde há, a invasão das Américas, bem como, escravização de africanos trazidos à força bruta ao Brasil, posteriormente, as I e II guerras mundiais, ditaduras, e outras situações atreladas a problemáticas econômicas, religiosas e práticas xenofóbicas compõem, dentre os diversos quadros, razões de migrações.

Ao destacarmos a contemporaneidade, observamos que os fluxos migratórios, inicialmente, se direcionaram para países considerados desenvolvidos, porém, países em desenvolvimento, como o Brasil, tem recebido todos os anos migrantes e refugiados de diferentes culturas e línguas, como aponta Jardim (2017). Se em dado momento histórico populações europeias encontram no Brasil oportunidade de emprego e estabelecimento de uma vida melhor e recebem apoio do governo para fixação de moradia em nosso país, de outro lado, temos refugiados da América Latina, Ásia e África que tem adentrado ao Brasil em busca de condições de sobrevivência e acolhimento para seu processo de resiliência e (re)construção identitária.

Após passarmos um período em diferentes países do Oriente Médio, trabalhando em organizações não governamentais (ONG's) como voluntários em programas de ensino de língua inglesa ofertado para refugiados, percebemos que nosso país, o Brasil, tem sido casa para vários outros refugiados, como citado anteriormente, de diferentes culturas e línguas, à destacar os povos árabes. Estes ao entrarem em nosso país, além de toda situação de vulnerabilidade que enfrentam - por exemplo, contexto de guerra civil -, surge também a distância entre a língua portuguesa e a árabe, seja na escrita ou fala, adicionada aos aspectos culturais. Com isso, o Português como Língua de Acolhimento - PLAC e/ ou as Línguas Adicionais - LA's têm um papel central de (re)integração desses sujeitos ao novo contexto social.

Diante do exposto, nesta pesquisa, abordaremos a importância do ensino/aprendizagem e aquisição da língua(gem) para o processo da resiliência de pessoas em situação de refúgio, em especial, aos falantes do árabe. Dando visibilidade aos trabalhos e materiais teóricos 
dispostos à temática, bem como, cooperando para uma reflexão mais ampla sobre as ações desenvolvidas por órgãos governamentais e não governamentais no Brasil, levando em consideração nossas experiências enquanto professores de Língua Inglesa em ONG's no Oriente Médio.

\section{REFUGIADO E CONTEMPORANEIDADE}

Embora estejamos ouvindo constantemente em telejornais e notícias online sobre refugiados que tentam fazer travessias cotidianamente de seu país para outro, muitos de nós, espectadores, não compreendemos bem o que a palavra refugiado representa, enquanto que para alguns refugiados indicam ameaça a seu país, outros os enxergam como dignos de compaixão, não compreendendo o(s) contexto(s) que levam a necessidade de encontrar refúgio em outro país. O Alto Comissariado das Nações Unidas para Refugiados (ACNUR), nos apresenta refugiados como pessoas que:

Estão fora de seu país de origem devido a fundados temores de perseguição relacionados a questões de raça, religião, nacionalidade, pertencimento a um determinado grupo social ou opinião política, como também devido à grave e generalizada violação de direitos humanos e conflitos armados. (ACNUR, 2020, P.08)

Compreendemos então, que o refugiado não está fora de seu país de origem de maneira voluntária, mas, é forçado a sair dele e buscar abrigo em outra nação. Porém, nem sempre o deslocamento para o próximo país é pacífico, haja vista que muitos refugiados até mesmo morrem na travessia devido às condições de fuga, como afirmam os dados do relatório Jornadas Desesperadas:

Ao longo de 2018, houve mudanças significativas no padrão de rotas tomadas por refugiados e migrantes que se dirigiam para a Europa. [...] Embora as chegadas tenham caído significativamente em comparação com o grande número de pessoas que chegaram à Itália todos os anos entre 2014-2017 ou à Grécia em 2015, as viagens foram mais perigosas do que nunca. Estima-se que 2.275 pessoas morreram no Mediterrâneo em 2018 - uma média de seis mortes por dia. (DESPERATE JOURNEYS, 2018) [tradução nossa].

Nos deparamos então com uma espada de dois gumes, pois, enquanto há a possibilidade de sofrer várias violações em seu país de origem prolongando sua estada, o processo de fuga carrega em si vários desafios e até mesmo a possibilidade de não alcançar o destino almejado. Observando tais aspectos, destacamos a importância da adoção de mais políticas públicas de esfera mundial, e não apenas resoluções normativas federais, principalmente, por países desenvolvidos, pois, nota-se que, apesar dos avanços da OIM (Organização Internacional para as Migrações), ainda há a necessidade de um olhar mais atento para questões que envolvam refugiados de forma a preservar suas vidas .

É importante salientar que embora já exista a expressão "migrantes forçados" para se remeter a refugiados, o ACNUR nos traz importantes diferenças a serem consideradas entre migrantes e refugiados, sendo que:

Enquanto as pessoas refugiadas estão em uma situação muito vulnerável, pois não têm proteção de seus respectivos países e sofrem ameaças e perseguições, os migrantes internacionais escolheram viver no exterior principalmente por motivações econômicas, podendo voltar com segurança a seu país de origem se assim desejarem. 
Estes não recebem assistência e proteção do ACNUR, pois não estão sob seu mandato. (ACNUR, 2020, P.10)

Logo, observamos que cidadãos locais, migrantes e refugiados têm convivido juntos, construindo, nem sempre de maneira amigável, uma rede de língua (gens) e interculturalidade, mas, destacamos a situação do refugiado como aquela de maior vulnerabilidade, pois vai além de questões econômicas, mas a perda de uma vida construída e estabelecida em seu país, relações que são perdidas, modos de vidas que têm de ser reconfigurados, não por vontade própria.

Tal compreensão e entendimento, pode nos conduzir à reflexão mais cuidadosa em torno da temática refúgio, e, tudo o que é ou será produzido/veiculado nos meios de comunicações acerca dela. Tendo em vista que é real os malefícios que a internet tem gerado nos últimos anos, fazendo com que assuntos da "contemporaneidade" sejam mais polarizados e/ou até mesmo demonizados, como aponta Bauman (2017). A continuidade dessa problemática, afasta cada vez mais a população do país de acolhimento e/ou global, e os representantes governamentais, da busca de soluções conjuntas que gerem maiores benefícios para refugiados, benefícios estes que possam ir além da abertura ou resgates nas fronteiras às pessoas refugiadas, especialmente no Brasil, país que não possui ainda, políticas públicas de nível federativo, apenas resolução normativa - qual alguns Estados demonstram pouca ou nenhuma preocupação - contando com o apoio dos órgãos de fiscaliz (ação), à exemplo, CONARE criado em 1997 conforme a Lei nº 9.474, vinculado ao Ministério da Justiça e Segurança Pública; e que tem assistência dos ministérios de Relações Exteriores; Trabalho; Educação; Saúde e a Polícia Federal.

Apresentamos também, a participação da sociedade civil por meio das ONG's, pertencentes ou não a agremiações religiosas, que exercem ações muito humanizadoras e significativa, a citar os representantes da Caritas ${ }^{1}$ Rio de Janeiro e da Caritas São Paulo e o Abraço Cultural $^{2}$, situada também nos Estados acima citados, que oferecem a refugiados que já aprenderam o português a oportunidade de ensinar a(s) língua(s) de seu país de origem, reforçando a importância da cultura do refugiado e sua capacidade de se refazer por meio do ensino remunerado de línguas.

Ainda sobre a celeuma de desinformação sobre a temática da migração forçada e refúgio, qual o Brasil, por sua vez, apresenta um certo sensacionalismo ou inibição das ações governamentais ou civis, ocasionando um olhar à situação dos refugiados por vias econômicas e/ou jurídicas apenas; econômicas quando se compreende que o grupo poderá ter privilégios, seja no território acolhedor ou supervisionados por instâncias internacionais, já que este sujeito apresenta uma condição desumana assustadora. E jurídicas, quando tratamos de direito internacional e/ou sobre processos de admissão de uma pessoa em território estrangeiro por meio dos trâmites legalmente administrativos, exemplo, evitando infrações penais. O que transforma/deixa a vida desse grupo social, muito mais complexa do que já é. Arantes, Deusdará e Brenner (2016, p. 1197) reforça dizendo:

tal abordagem privilegia tão-somente o âmbito das políticas de segurança nacional, relegando as condições de vida de quem é forçado a deixar seu país de origem, vitimado

\footnotetext{
${ }^{1}$ Disponível em: http://caritas.org.br/area-de-atuacao/6. Acesso em 25 de jul. de 2020.

2 Disponível em: https://www.abracocultural.com.br/sobre-o-curso/\#professores. Acesso em 25 de jul. de 2020.
} 
por perseguição social, religiosa, política, ambiental como uma narrativa dramática remetendo ao plano estritamente individual.

Os autores afirmam também que:

[...] a ausência de políticas de acolhimento e bem-estar social, previstas pelos fóruns internacionais, conduz grupos de refugiados a condições precárias de inserção na vida social." (ARANTES etal, 2016, p. 1199)

Aqui, apontamos a importância da interdisciplinaridade para configuração atitudinal e de narrativa dialógica, considerando que a ampliação discursiva e atuação demonstra ser um meio de construção mais efetiva a curto, médio e longo prazo; permitindo um crescimento micro à macro político de ações e desloca a situação dos refugiados para o campo de questões humanitárias contemporâneas.

Quais, nós atores da área da linguagem, temos e teremos sempre um papel atitudinal no que diz respeito à políticas de acolhimento e bem-estar social que contemplam os refugiados pela razão de acreditarmos que a educação mostra ser o meio possível de alcançar uma transformação social, pois, como disse Paulo Freire (2002, p. 12): "ensinar não é transferir conhecimento, mas criar as possibilidades para a sua produção ou a sua construção" -, então, o ensino-aprendizagem de uma língua produz um sujeito inscrito em condições sócio-históricas específicas, levando em conta que cada refugiado tem um processo único diante de sua condição vulnerável, conforme a ideia apresentada por Arantes, Deusdará e Brenner (2016) em seu artigo.

Ademais, enfatizamos mais uma vez que, a atuação dos professores de língua(gens) e, com base em nossas experiências no ensino de língua inglesa para refugiados falantes do árabe fora do Brasil, nos mostra o quanto podemos cooperar com o processo de identidade e cultura, através da promoção de ensino-aprendizagem de uma língua, seja de acolhimento, adicional ("estrangeira") para a integração do sujeito refugiado à sociedade.

Acreditando nos pressupostos acima, reforçamos a importância do(s) processo(s) de formação docente nos contextos de língua materna ou não materna, observando que instituições de ensino superior ainda não ofertam de forma massiva componentes curriculares quais preparem e/ou conscientizem os estudiosos das línguas(gens) sobre o ensino de línguas para refugiados, migrantes ou imigrantes, considerando as perspectivas de Português como Língua de Acolhimento - PLAC, Português como língua estrangeira - PLE e línguas adicionais - LA's. Caracterizando a necessidade de ampliação da compreensão do que é política linguística e sua força nas questões da justiça social, Kaplan e Baldauf Jr., apresentam política linguística como:

[...] um conjunto de ideias, leis, regulamentos, regras e práticas que visam implementar, na sociedade, grupo ou organização sociopolítica, as mudanças linguísticas planejadas. Somente quando tal política existe é que algum tipo de avaliação efetiva do planejamento [linguístico] ocorre" (1997, p. xi apud RIBEIRO DA SILVA, 2013, p. 291).

Quando se compreende isso, se percebe sua força nas questões da justiça social, salientamos que é significativo o que já vem sendo feito, contudo, existe uma necessidade de aprimoramento, especialmente, no Brasil, à exemplo, sobre as variantes do Português brasileiro.

Portanto, destacamos a participação e o trabalho das entidades, as ONGs, de promoção à educação e profissionalização neste processo de política pública e linguística, que produzem 
uma remodelação à pedagogia sistematizada, permitindo uma pedagogia social qual possibilita a integração dos indivíduos para sua formação em diferentes contextos, sejam para os docentes e/ou alunos envolvidos, como aborda Natal e Silva (2015).

\section{A IMPORTÂNCIA DA LÍNGUA(GEM) NO PROCESSO DE RESILIÊNCIA DE REFUGIADOS}

Quando trazemos à tona a temática "refúgio" em contexto brasileiro, observamos que, embora, muitas vezes, refugiados procurem se abrigar em países vizinhos a seu país de origem, muitos deles têm buscado o Brasil como um lugar para a reconstrução de suas vidas. Nos últimos anos um grande contingente de refugiados tem buscado acolhida no Brasil, dados da Comitê Nacional para os Refugiados - CONARE (2018), nos mostram que 36\% das pessoas com status de refugiados no Brasil são de origem síria, sendo que os outros $64 \%$ é dividido entre congoleses, angolanos, colombianos, venezuelanos, dentre outras nacionalidades.

Logo, quando consideramos essas pessoas de diversas nacionalidades, línguas e culturas, percebemos que embora cada grupo de refugiados possuam suas particularidades e idiossincrasias, a aprendizagem da língua de acolhimento é essencial para o processo de resiliência desses grupos, gerando a possibilidade de se reinventar no Brasil.

Quando pensamos em ensino de línguas para refugiados, trazemos Pereira (2017), que nos esclarece sobre a diferença entre ensinar línguas em uma perspectiva de língua de acolhimento e de língua estrangeira, ambas se diferem tanto pelo contexto quanto pelo objetivo do ensino/aprendizagem, de acordo com a autora supracitada, o ensino de língua de acolhimento visa a integração do refugiado no país de acolhida, de maneira a proporcionar uma melhor qualidade de vida.

Pesquisas da British Council (2018), nos trazem que além do processo de integração desse refugiado ao sistema econômico e cultural, a língua(gem) pode auxiliar no processo de resiliência dessas pessoas nessa nova cultura. Tendo em vista as condições de vulnerabilidade social, a língua passa a ser o meio ao qual haverá a reconstrução identitária, conforme o documento da British Council (2018, p.6), o qual reforça a ideia de que "a língua é uma parte essencial da nossa vida individual e comunitária, além de ser uma ferramenta essencial para a aprendizagem." [Tradução nossa]. Outrossim, levando em consideração que este trabalho busca cooperar com as pesquisas sobre Language for Resilience Research, apresentamos aqui, uma definição de resiliência que mais se adequa a nossa perspectiva discursiva, além de que, esse termo é muito dinâmico e precisa ser bem compreendido, portanto, Brasil (2019, p.296) descreve que "[...] A resiliência não é um processo que surge do externo para o interno, e sim algo que desabrocha internamente na busca de uma superação com apreensão de conhecimentos e ações."

Com base nessa premissa, que a superação do contexto de vulnerabilidade e demais problemáticas adquiridas do processo da vida em fuga, pode emergir da apreensão de conhecimentos e ações, reafirmamos o pensamento/ideia de que língua, principalmente o Português como Língua de Acolhimento - PLAC e/ou Línguas Adicionais - LAs, maximizam a inserção da pessoa em situação de refúgio na nova comunidade estrangeira. Pois, a língua é um processo dialógico e responsivo, e alinhada à temática desta pesquisa, ela [a língua] se torna uma fundadora de alteridade, seja ela contínua ou provisória. Mohammed Ateek (2018), ao escrever um dos textos que constitui o material Language for Resilience: Cross-disciplinary perspectives on the role of language in enhancing the resilience of refugees and host communities (2018), nos diz que o refugiado já é forçosamente inserido em uma nova sociedade 
estando em situação de vulnerabilidade, então, não conhecer a língua do novo país os deixa em uma situação ainda mais vulnerável, afinal, mesmo que este possa ter os mesmos direitos que o cidadão do país de acolhimento, não ter a oportunidade de aprender a nova língua pode colocá-lo em situações difíceis de se lidar. Quando observamos a situação de refugiados de fala árabe, levando em consideração nossas experiências no Oriente Médio e no Brasil, fazemos uso de Bulla et al (2018), que nos traz que quanto mais distante a língua do refugiado for da língua do país de acolhimento, sua vulnerabilidade pode ser ainda mais acentuada, as autoras citam por exemplo, o caso de crianças de fala árabe que estão em escolas públicas brasileiras e não recebem nenhuma preparação para a fala do português, o que acaba comprometendo no rendimento escolar dessas crianças; Quando pensamos no refugiado árabe adulto, percebemos que esse indivíduo nem sempre terá acesso ao sistema educacional que o ensine o português, sendo que, a aprendizagem se dará apenas pela possível aquisição. Aqui cabe a reflexão que, esse processo de aquisição, seja por meio da PLAC ou LA's, nasça com o propósito - não romantizado - de instauração de seu uso em situações concretas. Porque, como diz Bakhtin (2004, p. 108 apud ARANTES et al, 2016, p. 1201) "[...] a língua, como sistema de formas que remetem a uma norma, não passa de uma abstração". Visto que o sujeito em situação de refúgio encontra-se no país de acolhimento sem perspectivas positivas de suas vidas, além, de se sentir coercitivamente conduzido a usar /aprender uma língua que não fazia/faz parte de seus planos. E neste caso, precisamos quebrar barreiras, que a British Council (2018), descreve como ação fundamental para a "produção"/desabrochamento da resiliência.

Outra reflexão válida, se trata dos materiais didáticos voltados a este grupo social, como já dito, que o ensino de língua de acolhimento não é o mesmo que ensino de língua estrangeira, cabendo aqui, outra vez, a necessidade de que as instituições de formação docentes, junto aos órgãos governamentais de assistência à pessoas em situação de refúgio e migração, devem ser o meio da política pública de âmbito educacional, sob o que rege o suporte teórico-prático, primeiro aos alunos das licenciaturas para uma formação com mais responsabilidade social, especialmente os da área das língua(gens); segundo aos espaços de formação e/ou assistencialismo destes grupos, tendo em vista que refugiados não podem ser colocados em um único grupo, mas são pessoas de diferentes nacionalidades que trazem em si diferentes aspectos linguísticos e culturais, logo há a necessidade de preparação tanto de profissionais para o ensino de PLAC e LA's para essas pessoas, levando em consideração cada grupo e suas variações; Observamos também, por meio de nossas experiências, que muitas pessoas refugiadas já possuem uma formação acadêmica em seu país de origem, assim, entendemos que não apenas o ensinar, mas também temos a aprender com essas pessoas e utilizar o ensino de PLAC e LA's de uma maneira também a reforçar e possibilitar novas oportunidades levando em consideração todo o conhecimento e formação que muitos refugiados já possuem.

\section{CONSIDERAÇÕES FINAIS}

Por fim, através dos dados e experiências relatadas neste trabalho, se pretende contribuir na compreensão e progresso de Language for Resilience Research - perspectiva apresentada pela British Council -, considerando que o Brasil tem sido um espaço geográfico, buscado e alcançado por grupo de refugiados oriundos de diversos povos e línguas, bem como migrantes. Demarcando seu papel, como país acolhedor - embora ainda com deficiência no tocante à política pública voltada para este grupo social -, e, frente às questões humanitárias contemporâneas. 
Outro ponto, proporcionando a fomentação com amplitude da compreensão de língua(gem) através de condições sócio-históricas específicas na vida da pessoa na condição de refugiado, levando em consideração o mundo interior e a reflexão de cada indivíduo, em especial, no processo ensino-aprendizagem de uma língua. Pois, a língua(gem), será a ferramenta essencial no acolhimento e de desabrochamento da resiliência para estes sujeitos, quais são pertencentes de variadas culturas, povos e línguas.

Com reflexão sobre o investimento na formação de professores para lecionar o português como língua de acolhimento para refugiados e até mesmo que os cursos de formação em línguas estrangeiras, também ofereçam a oportunidade de preparação para o ensino de línguas adicionais para essas pessoas, ocasionando espaço na grade curricular das universidades para este tema, levando em consideração os aspectos da interculturalidade, como aponta Mendes (2011). Entendemos a necessidade de políticas públicas e linguísticas para que a aprendizagem da língua de acolhimento seja um direito garantido a todos que precisem do Brasil, principalmente, os refugiados por apresentarem maior vulnerabilidade social (a citar: linguística, econômica, psicológica, etc.).

Com esta pesquisa pretendemos levar ao conhecimento dos leitores o tema da migração e refúgio de forma a incitar novas ações para que integração do refugiado na sociedade brasileira possa acontecer, quebrando barreiras causadas pela xenofobia e, entendendo que independente de nacionalidade, cultura e línguas, somos cidadãos do mundo e podemos utilizar do conhecimento e da prática para auxiliar o próximo.

\section{REFERÊNCIAS}

Arantes, Poliana Coeli Costa; Deusdará, Bruno; Brenner, Ana Karina. (2016) Língua E Alteridade Na Acolhida A Refugiados: Por Uma Micropolítica Da Linguagem. Fórum Linguistic., Florianópolis, V.13, N.2, P.1196 - 1207, Abr./Jun.2016. Acesso: Ago. 2020.

Ateek, M. (2018). Home And Shared Language In The Context Of The Syrian Refugee Crisis. In: British Council Org. Language For Resilience: Cross-Disciplinary Perspectives On The Role Of Language In Enhancing The Resilience Of Refugees And Host Communities. Edited By Dr Tony Capstick. Disponívelem:<Https://Www.Rescuerefugees.Eu/Wpcontent/Uploads/2018/12/Language_For_Resilien ce_-_Cross-Disciplinary_Perspectives_0.Pdf> Acesso: Ago. 2020.

Bauman, Z. (2017). Estranhos À Nossa Porta. Tradução Carlos Alberto Medeiros - 1. Ed. - Rio De Janeiro: Zahar. Bulla, G. S.; Silva, R. L. E.; Lucena, J. C.; Silva, L. P. (2017) . Imigração, Refúgio E Políticas Linguísticas No Brasil: Reflexões Sobre Escola Plurilíngue E Formação De Professores A Partir De Uma Prática Educacional Com Estudantes Haitianos. Organon, V. 32, P. 1-14.

Brasil, Tatiana Lima. (2019). Resiliência Integral: Um Caminho De Possibilidades Para Formação Humana De Futuros Docentes. Tese (Doutorado) - Universidade Federal De Pernambuco, Ce. Programa De PósGraduação Em Educação. Disponível Em:<Https://Vdocuments.Mx/Reader/Full/Universidade-FederalDe-Pernambuco-Centro-De-A-Minha-Famlia-Por-Serem-Humanos> Acesso: Ago. 2020.

British Council Org. (2018). Language For Resilience: Cross-Disciplinary Perspectives On The Role Of Language In Enhancing The Resilience Of Refugees And Host Communities. Edited By Dr Tony Capstick. Disponível

Em:<Https://Www.Rescuerefugees.Eu/Wpcontent/Uploads/2018/12/Language_For_Resilience__Cross-Disciplinary_Perspectives_0.Pdf $>$ Acesso: Ago. 2020.

British Council Org. (2016) Language For Resilience: The Role Of Language In Enhancing The Resilience Of Syrian Refugees And Host Communities. With A Foreword By Unhcr. Disponível

Em:<Https://Www.Britishcouncil.Org/Sites/Default/Files/Language_For_Resilience_Report.Pdf > Acesso: Ago. 2020.

Conare. Relatório (2018). Disponível Em: Https://Www.Acnur.Org/Portugues/2019/07/25/Governo-E-AcnurLancam-Relatorio-Refugio-Em-Numeros-E-Plataforma-Interativa-Sobre-Reconhecimento-DaCondicao-De-Refugiado-No-Brasil/. Acesso Em Set. 2020.

Desperate Journeys - Unhcr: Refugees And Migrants Arriving In Europe And At Europe's Borders. January - December 2018. Disponível Em: <Https://Www.Unhcr.Org/Desperatejourneys/\#Ch2>. Acesso Em Nov. 2020.

Freire, Paulo. (1996). Pedagogia Da Autonomia: Saberes Necessários À Prática Educativa. 2002. 25a. Ed. São 
Paulo: Paz E Terra. (Coleção Leitura). Disponível Em: <Http://Www.Apeoesp.Org.Br/Sistema/Ck/Files/4\%20freire_P_\%20pedagogia\%20da\%20autonomia.Pdf>. Acesso Em Nov. 2020.

Jardim, D.F. (2017). Imigrantes Ou Refugiados? Tecnologias De Controle E As Fronteiras. Jundiaí, Paco Editorial.

Mendes, E. (Ed.). (2011). Diálogos Interculturais: Ensino E Formação Em Português Língua Estrangeira. Campinas, Sp: Pontes Editores. 310 Pp. Isbn: 978-85-7113-362-4

Natal, Marinice.; Silva, Daniela De Oliveira Santos Da Silva. (2015). Formação Docente Para A Responsabilidade Social: A Interlocução Da Formação Do Cidadão Em Diferentes Contextos. Educere - Xii Congresso Nacional De Educação. Pucpr 26 A 29/10/2015. Issn 2176-1396. Acesso Em Ago. 2020.

Ribeiro Da Silva, Elias. (2013). A Pesquisa Em Política Linguística: Histórico, Desenvolvimento E Pressupostos Epistemológicos. Trab. Ling. Aplic., Campinas, N(52.2): 289-320, Jul./Dez. 2013. Acesso Em Ago. 2020. 